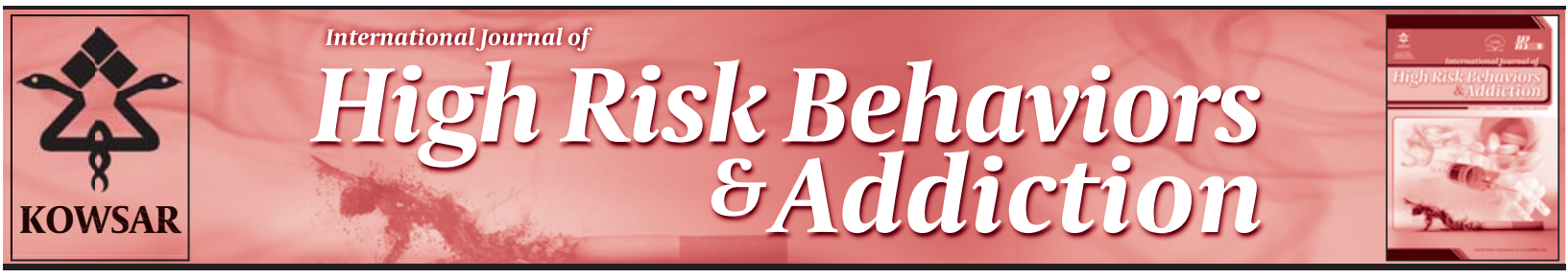

\title{
A Quantitative and Qualitative Study of Rat Testis Following Administration of Methadone and Buprenorphine
}

\author{
Zahra Heidari ${ }^{1}$, Hamidreza Mahmoudzadeh-Sagheb ${ }^{{ }^{*}}$, Farhad Kohan ${ }^{1}$ \\ ${ }^{1}$ Department of Histology, Faculty of Medicine, Zahedan University of Medical Sciences, Zahedan, IR Iran
}

\begin{tabular}{l}
\hline A R T I C L E I N F O \\
\hline Article type: \\
Original Article \\
\hline Article history: \\
Received: 09 Jul 2011 \\
Revised: 11 Sept 2011 \\
Accepted: 25 Nov 2011 \\
\hline
\end{tabular}

\section{Keywords:}

Buprenorphine

Methadone

Testis

Histopathology

\begin{abstract}
A B S T R A C T
Background: Opiate abuse is a matter of serious concern in adolescent men. The primary drugs used in the treatment of opiate addiction are methadone and buprenorphine. Objectives: This study was undertaken to determine the quantitative and qualitative changes in rat testes after methadone and buprenorphine administration.

Materials and Methods: In this experimental study, 15 male Wistar rats, each weighing 250 $\pm 15 \mathrm{~g}$, were selected and randomly divided into 3 groups $(n=5)$. The first group received an intraperitoneal dose of $0.5 \mathrm{mg} / \mathrm{kg} /$ day methadone and the second group received an intraperitoneal dose of $30 \mathrm{mg} / \mathrm{kg} /$ day buprenorphine for 15 days each. The third group (control) received normal saline injections. After the last injection dose, the rats were sacrificed and their testes were removed, weighed, and fixed in modified Lillie's solution, and embedded in 3.5\% agar, after which 1-mm slices perpendicular to the long axis of the testes were prepared using a tissue slicer. Then, on the basis of Cavaleri's principle, the testis volume was calculated by point-counting method. For histological analysis, systematic random samples of each testis were selected, processed, and stained by hematoxylin and eosin (H\&E) and periodic acid schiff(PAS) methods. The results obtained for the 3 groups were compared using nonparametric Kruskal-Wallis test. $P<0.05$ was considered as the level of significance.

Results: Stereological analysis of rat testes showed no significant effect of methadone and buprenorphine administration on the testis volume $(P>0.05)$. However, microscopic studies of rat tissues in the methadone-administered group showed atrophic seminiferous tubules, reduction of sperm stem cells, destruction of Sertoli cells, irregularities in the basement membrane of seminiferous tubules, cellular degeneration of spermatogonia and primary spermatocytes, and significantly fewer spermatozoids than in the control group. Furthermore, in the methadone-administered group, the germinal cells of seminiferous tubules were damaged and extensively detached from the basement membrane and the vessels of the interstitial tissue were congested. Microscopic studies of the buprenorphineadministered group showed no significant changes in the basement membrane, seminiferous tubules, Sertoli cells, interstitial tissue, and sperms.

Conclusions: Buprenorphine is more suitable for treating opiate addiction in males since it does not affect normal testicular structure and function.
\end{abstract}

Copyright @ 2012 Kowsar Corp. All rights reserved.

\begin{abstract}
- Implication for health policy/practice/research/medical education:
This article focuses on quantitative and qualitative changes in rat testes after methadone and buprenorphine administration. Considering high prevalence of Opiate abuse and treatment of Opiate addiction among adolescent men, it is necessary to find out the effects of these drugs on testes. This study is recommended to Basic medical sciences researchers, Urologists, Psychologists, and also for informing the general population, particularly the youth, of the probable consequences of opioids drugs.
\end{abstract}

\section{- Please cite this paper as:}

Heidari Z, Mahmoudzadeh-Sagheb H, Kohan F. A Quantitative and Qualitative Study of Rat Testis Following Administration of Methadone and Buprenorphine. Int J High Risk Behav Addict. 2012; 1(1):14-7. DOI: 10.5812/ijhrba.4119

\footnotetext{
* Corresponding author: Hamidreza Mahmoudzadeh-Sagheb, Department of Histology, Zahedan University of Medical Sciences, Zahedan, IR Iran. Tel: +98-5413414572, Fax:+98-5413414572, E-mail: histology@ymail.com
}

DOI:10.5812/ijhrba.4119

Copyright $\odot 2012$ Kowsar Corp. All rights reserved. 


\section{Background}

Opiate abuse has been a matter of serious concern in adolescent men (1). The primary drugs used in the treatment of opiate addiction are the pure $\mu$-opioid receptor agonist, methadone, and the partial $\mu$-opioid receptor agonist buprenorphine, both of which dissociate slowly from the receptors and have long half-lives $(1,2)$. Methadone is a long-acting opiate agonist that has been used as the main agent for detoxification in heroin-dependent patients (3). Many studies have demonstrated the efficacy of methadone in decreasing illicit drug consumption and criminal behavior, and in improving the rehabilitation of patients with intravenous opiate addiction (3-5). However, this therapeutic method is associated with several problems, including limited patients and community acceptance, and it is not an optimal treatment choice for all subjects $(3,6,7)$. The number of addicts maintained on methadone has increased over the last few decades. However, many addicts have untreated hypogonadism. Apart from sexual dysfunction, these patients may show testosterone deficiency and several associated physical disorders such as osteoporosis, infertility, impairment of testicular volume, and decrease in strength and muscle mass (1). Buprenorphine is a new drug for maintenance therapy in patients with opioid dependence. Since 2001, this drug has been available for the treatment of heroin addiction (3). It is a mixed agonist-antagonist opioid with low intrinsic activity and high affinity for the $\mu$-opioid receptor and with no intrinsic activity, but high affinity, for the $\kappa$-opioid receptor (1). Buprenorphine has a good safety profile, low abuse potential, and the capability to suppress opioid withdrawal symptoms, all of which make it very suitable for the maintenance therapy of heroin addicts. Additionally, it blocks the effects of concurrently administered opioids, and thereby, reduces the risk of relapse in buprenorphine-maintained patients. It has been firmly established that buprenorphine is a more efficient drug than methadone for treatment of opioid dependence (8-10).

\section{Objectives}

This study was performed to determine the quantitative and qualitative changes in rat testes following administration of methadone and buprenorphine.

\section{Materials and Methods}

In this experimental study, 15 male Wistar rats, each weighing $250 \pm 15 \mathrm{~g}$, were selected from the animal house of the Research center of Zahedan University of Medical Sciences (Iran). The rats were acclimatized in a constant cycle of $12 \mathrm{~h}$ light and $12 \mathrm{~h}$ darkness in an animal house maintained at $22 \pm 2^{\circ} \mathrm{C}$; the animals had free access to standard laboratory diet and water. After 2 weeks of acclimatization, the rats were divided randomly into 3 groups $(n=5)$. The first and second groups were intraperitoneally administrated $0.5 \mathrm{mg} / \mathrm{kg} /$ day methadone, and $30 \mathrm{mg} /$ $\mathrm{kg} /$ day buprenorphine, respectively, for 15 days (11). The third group (control) received normal saline injections. After the last injection, the rats were killed and their testes were removed, weighed, and fixed in modified Lillie's solution, and embedded in 3.5\% agar, after which 1-mm slices perpendicular to the long axis of the testes were prepared using a tissue slicer. The testis volume was calculated on the basis Cavaleri's principle by using the point-counting method. For histological analysis $(5,6)$, systematic uniform random samples of each testis were selected, histologically processed, and stained by hematoxylin and eosin (H\&E) and periodic acid schiff (PAS) methods. In order to project the entire section image on the screen, a modified slide projector was used. Point counting using Cavaleri's principle was employed to estimate the volume of testis using the formula:

$$
\boldsymbol{V}=\frac{\sum_{\mathrm{i}=1}^{\mathrm{m}} \mathrm{P} \cdot \mathrm{a} / \mathrm{p} \cdot \overline{\mathrm{t}}}{\mathrm{M}^{2}}
$$

Where $\sum \mathrm{P}$ is the number of points hitting the object transects, a/p is the area associated with each point in the grid, $\overline{\mathrm{t}}$ is the mean distance between the sections and, $\mathrm{M}$ is the linear magnification of the image. The coefficient error of point counting was calculated as described previously $(11,12)$. Intergroup comparisons were performed using nonparametric statistical test of Kruskal-Wallis and Mann-Whitney U test. $P<0.05$ was considered as the significant level.

\section{Results}

Stereological evaluation of the testis volume in the methadone-administered group and the buprenorphine-adminsitered group was not significantly different from that in the control group $(P>0.05)$ (Table 1).

Figure $1 A$ and Figure $1 B$ show the normal appearance of a rat's testis in the control group. Histopathological study

\begin{tabular}{|c|c|c|}
\hline & Testis Volume & $\mathbf{C E}$ \\
\hline Methadone, Mean \pm SD & $1774 \pm 102.7$ & \\
\hline $\mathrm{M} 1^{\mathrm{a}}$ & 1712 & 0.04 \\
\hline M2 & 1760 & 0.04 \\
\hline M3 & 1696 & 0.05 \\
\hline M4 & 1824 & 0.03 \\
\hline M5 & 1936 & 0.04 \\
\hline Buprenorphine, Mean \pm SD & $1785 \pm 101.6$ & \\
\hline $\mathrm{B} 1^{\mathrm{a}}$ & 1792 & 0.05 \\
\hline B2 & 1632 & 0.05 \\
\hline B3 & 1840 & 0.03 \\
\hline B4 & 1904 & 0.06 \\
\hline B5 & 1760 & 0.04 \\
\hline Control, Mean \pm SD & $1785 \pm 97.7$ & \\
\hline$C 1^{\mathrm{a}}$ & 1840 & 0.05 \\
\hline $\mathrm{C} 2$ & 1648 & 0.03 \\
\hline C3 & 1712 & 0.05 \\
\hline $\mathrm{C} 4$ & 1872 & 0.04 \\
\hline C5 & 1664 & 0.03 \\
\hline
\end{tabular}

${ }^{\mathrm{a}}$ Abbreviations: B, Buprenorphine; C, Control; M, Methadone 


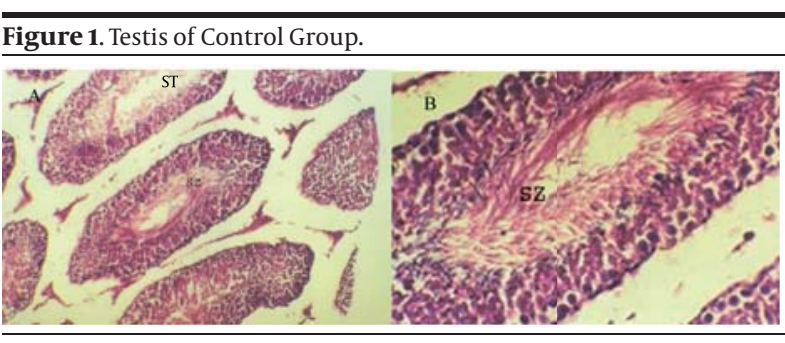

A. $250 \times$ hematoxyline and eosin (H\&E) Staining. Seminiferous tubule with compact epithelium, crowding of germ cells in different stages of spermatogenesis and matured spermatozoids in the Lumen; B. $400 \times$ hematoxyline and eosin (H\&E) Staining. Seminiferous tubule with apparent sperm lineage and matured spermatozoids in the lumen. ST, Seminiferous tubules; SZ, Matured spermatozoids.

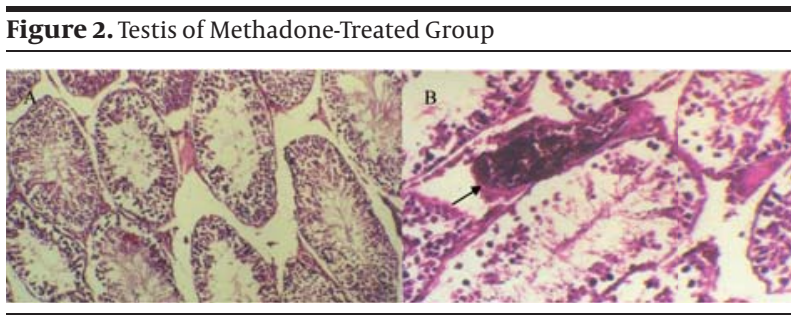

A. 250×. Hematoxylin \& Eosin Staining (H\&E). Atrophy in the wall of seminiferous tubules shows the reduction of sperm Lineage cells. Vacuolated wall of tubules shows destruction of Sertoli cells. Note congestion of vessels in interstitial tissue; B. 400×. H\&E staining. Seminiferous tubules with reduction in sperm stem cells and destroyed Sertoli cells. Severe Congestion in vessels of interstitial tissue (arrow).

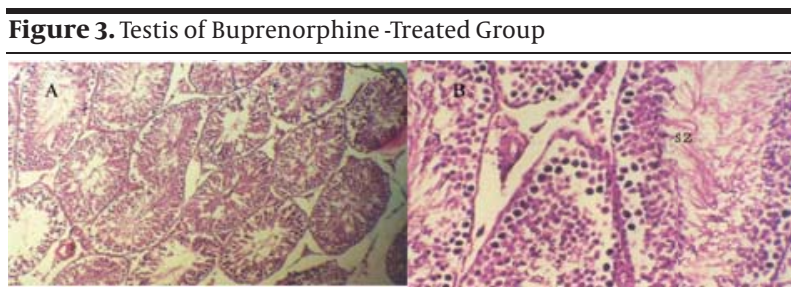

A. 250×. Hematoxylin \& Eosin (H\&E) staining. Seminiferous tubules in different stages of spermatogenesis; B. $400 \times$ H\&E staining. Seminiferous tubules with matured spermatozoids (SZ) in the lumen. There is no congestion in vessels of interstitial tissue. SZ, Matured spermatozoids.

of the testes in the methadone-administered group shows atrophy of the walls of seminiferous tubules and destruction of Sertoli cells (Figure 2A), irregularities in the basement membrane of seminiferous tubules, cellular degeneration of spermatogonia and primary spermatocytes, significant reduction of spermatozoids, and congestion of vessels in interstitial tissue (Figure 2B).

Microscopic studies in rat tissues showed that the basement membrane, seminiferous tubule, Sertoli cells, interstitial tissue, and sperms in the buprenorphine-administration group were not significantly different from those in the control group (Figure $3 A$ and Figure $3 B$ ).

\section{Discussion}

The present study indicates that the mean total testis volume of the rats in the methadone- and buprenorphine-treated groups showed no significant difference from that in the control group. However, some previous studies have reported that methadone and buprenorphine are opioids that have effects on spermatogenesis (6) and secondary sex organs (5). It seems probable that these drugs could affect testes volume. We believe that the dose and duration of the treatment with buprenorphine and methadone in our study may be insufficient for inducing gross anatomic changes in a rat's testis.

Microscopic examination of tissues showed that 0.5 $\mathrm{mg} / \mathrm{kg}$ methadone administration per day for 15 days arrested spermatogenesis, sloughed the germinal epithelium, destroyed Sertoli cells in seminiferous tubules, and caused thickening and irregularities in the basement membrane. The results of our study are in accordance with those obtained by Jean-L et al., who showed that methadone treatment caused testicular atrophy and decreased serum testosterone levels in a majority of infertile heroin addicts (8). Several investigations have shown that narcotics markedly reduce the structural and functional integrity of the secondary sex organs by causing pronounced reduction in serum testosterone levels ( 1 , $3,6)$. These drugs inhibit the secretion of luteinizing hormone (LH) by acting either in the hypothalamus or directly in the pituitary gland, which leads to reduced serum testosterone levels (5). Our study showed that the destructive effects of methadone on testes were more obvious than those of buprenorphine. Previous studies showed that both methadone- and buprenorphinetreated men had lower free testosterone, LH, and estradiol levels than those in the age-matched control groups. Methadone-treated men had lower testosterone levels than buprenorphine-treated and control-group men. Hypogonadotrophic hypogonadism was highly prevalent in men on methadone maintenance therapy (MMT). Evidence of the direct effects of opioids on testicular function has also been reported in animal studies (13). Another study suggests that buprenorphine, like other opiates, may cause the serum levels of testosterone to reduce below the normal range (14). This finding is supported by another cross-sectional study that showed that $28 \%$ of buprenorphine- and $65 \%$ of methadone-receiving patients had lower serum testosterone levels than those in age-matched patients in control group. Erectile dysfunction was higher in methadone-maintained patients than in buprenorphine-maintained and control-group men (13). On the other hand, Brown et al. found few cases showing sub-normal testosterone levels in men receiving methadone, found no evidence of a dose relationship to hypogonadism, and concluded that hypogonadism is no more common on men in MMT than in the general community (15). A cross-sectional study showed that the mean levels of testosterone in buprenorphine-treated patients were not significantly different from those in controls, but were significantly higher than the levels in methadone-treated patients (1). Opiates are known to cause loss of libido and erectile and ejaculatory dys- 
functions among men (16). It seems probable that buprenorphine causes less gonadal suppression than the other opioids. Opioids inhibit the release of hypophyseal gonadotrophins; thus, opioid-induced hypogonadism can be best described as hypogonadotrophic hypogonadism. The hypogonadotrophic effect of opioids can be observed even after the administration of a single opioid dose, both in laboratory animals and in humans (17). Buprenorphine's action as a partial opioid agonist might limit its suppression of gonadotrophin release. Thus, for the management of hypogonadism in men on MMT, one option can be transfer to buprenorphine therapy (1). Thickening and irregularity in the basement membrane of seminiferous tubules, spermatogenesis arrest, and sloughing of the germinal epithelium were the major microscopic changes we saw in the methadone group. Reuhla et al. (18) also showed thickening of the basement membrane of seminiferous tubules, reduction of tubular diameter and height of the germinal epithelium, cell-maturation arrest, and highest proportion of interstitial tissue in drug abusers. It is known that changes in the thickness of the basement membrane can impair testicular metabolism, and thus promotes enhanced germinal cell hypoplasia and tubular atrophy. The extent of testicular damage is closely related to the duration of drug consumption (2). Buprenorphine was less frequently related to histopathological changes in rat testis. Therefore, buprenorphine might be favored in the treatment of opioid dependence to prevent the clinical consequences of methadone-induced histological damages in the testes of patients. However, further research is needed to confirm these findings.

\section{Acknowledgments}

The Deputy Research of ZUMS financially supported this research. This article is the result of a university research dissertation (MD thesis).

\section{Authors' Contributions}

Z Heidari and H Mahmoudzadeh-Sagheb co-designed the study, supervised all the experimental design, analyzed the results, and wrote the manuscript. F Kohan participated in design, oversaw the animal injections and diet manipulations, assisted with tissue collection, processing and staining, and also prepared the final figures. All authors read, modified and approved the final version of the manuscript.

\section{Financial Disclosure}

None declared.

\section{Funding/Support}

The Deputy Research of ZUMS financially supported this research. This article is the result of a university research dissertation (MD thesis).

\section{Additional Information}

All animals received humane care according to the criteria outlined in the [Guide for the Care and Use of Laboratory Animals prepared by the National Academy of Sciences and published by the National Institutes of Health (NIH publication 86-23 revised 1985)].

\section{References}

1. Bliesener N, Albrecht S, Schwager A, Weckbecker K, Lichtermann D, Klingmuller D. Plasma testosterone and sexual function in men receiving buprenorphine maintenance for opioid dependence. J Clin Endocrinol Metab. 2005;90(1):203-6.

2. Sorge RE, Stewart J. The effects of long-term chronic buprenorphine treatment on the locomotor and nucleus accumbens dopamine response to acute heroin and cocaine in rats. J Pharmacol Biochem Behav. 2006;84(2):300-5.

3. Vigezzi P, Guglielmino L, Marzorati P, Silenzio R, De Chiara M, Corrado F, et al. Multimodal drug addiction treatment: a field comparison of methadone and buprenorphine among heroinand cocaine-dependent patients. J Subst Abuse Treat. 2006;31(1):37.

4. Plomp HN, Van Der Hek H, Ader HJ. The Amsterdam methadone dispensing circuit: genesis and effectiveness of a public health model for local drug policy. J Addict. 1996;91(5):711-21.

5. Schottenfeld R, Kleber H, editors. Methadone maintenance: Baltimore, Williams \& Wilkins, 1995.

6. Kolar AF, Brown BS, Weddington WW, Ball JC. A treatment crisis: cocaine use by clients in methadone maintenance programs. $J$ Subst Abuse Treat. 1990;7(2):101-7.

7. Hartel DM, Schoenbaum EE, Selwyn PA, Kline J, Davenny K, Klein RS, et al. Heroin use during methadone maintenance treatment: the importance of methadone dose and cocaine use. Am J Public Health. 1995;85(1):83-8.

8. Ling W, Charuvastra C, Collins JF, Batki S, Brown LS, Jr., Kintaudi $P$, et al. Buprenorphine maintenance treatment of opiate dependence: a multicenter, randomized clinical trial. J Addict. 1998;93(4):475-86.

9. Pani PP, Maremmani I, Pirastu R, Tagliamonte A, Gessa GL. Buprenorphine: a controlled clinical trial in the treatment of opioid dependence. J Drug Alcohol Depend. 2000;60(1):39-50.

10. Marsch LA, Bickel WK, Badger GJ, Jacobs EA. Buprenorphine treatment for opioid dependence: the relative efficacy of daily, twice and thrice weekly dosing. J Drug Alcohol Depend. 2005;77(2):195204.

11. Shahramian I, Mahmoudzadeh Sagheb H, Heidari Z. Volumentry of Brain of Rat Following Methadone and Buprenorphine Administration. Int J Pharmacol. 2006; 2(2):253-5.

12. Shahramian I, Mahmoudzadeh Sagheb H, Heidari Z. Volumetric Changes in the Kidney of Rats Following Administration of Methadone and Bupronorphin by Cavalier's Method. J Birjand Universitty of Medical Sciences. 2009.

13. Hallinan R, Byrne A, Agho K, McMahon CG, Tynan P, Attia J. Hypogonadism in men receiving methadone and buprenorphine maintenance treatment. Int J Androl. 2009;32(2):131-9.

14. Colameco S, Coren JS, Zimmerman DJ. Buprenorphine-induced Symptomatic Hypogonadism in Men: Case Reports and Discussion. J Addict Med. 2008;2(3):147-50.

15. Brown R, Balousek S, Mundt M, Fleming M. Methadone maintenance and male sexual dysfunction. J Addict Dis. 2005;24(2):91106.

16. Déglon JJ MJaIR. Methadone patients' sexual dysfunctions: Clinical and treatment issues. J Heroin Add \& Rel Clin Probl. 2004;6(3):17-26.

17. Zylicz Z. Opioid-induced hypogonadism: the role of androgens in the well-being and pain thresholds in men and women with advanced disease. J Adv in Palliative Med. 2009; 8 (2):57-62.

18. Reuhl J, Bachl M, Schneider M, Lutz F, Bratzke H. Morphometric assessment of testicular changes in drug-related fatalities. J Forensic Sci Int. 2001;115(3):171-81. 


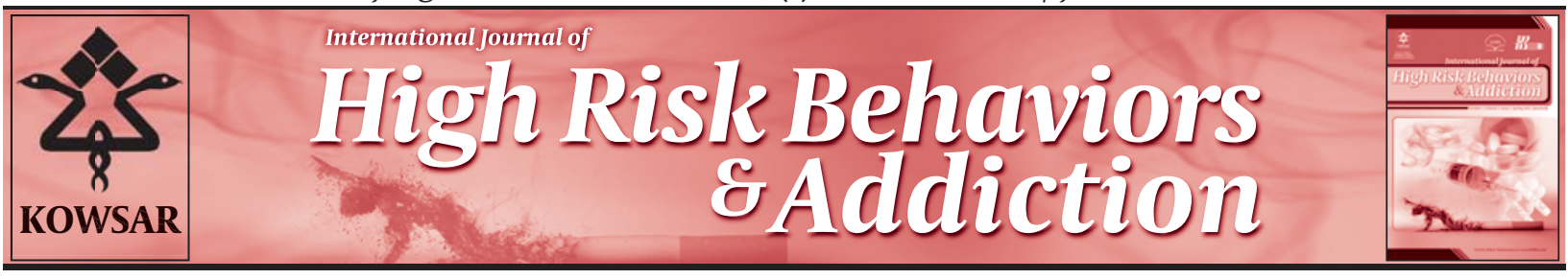

\title{
Evaluation of Nutritional Status in Drug Users Referred to the Center of Drug Dependency Treatment in Zahedan
}

\author{
Mansour Karajibani ${ }^{1^{*}}$, Farzaneh Montazerifar $^{1}$, Mansour Shakiba ${ }^{2}$ \\ ${ }^{1}$ Department of Nutrition and Zahedan Health Promotion Research Center, School of Medicine, Zahedan University of Medical Sciences, Zahedan, IR Iran \\ ${ }^{2}$ Department of Psychiatry, Zahedan University of Medical Sciences, Zahedan, IR Iran
}

\begin{tabular}{l}
\hline A R T I C L E I N F O \\
\hline Article type: \\
Original Article \\
\hline Article history: \\
Received: 25 Jul 2011 \\
Revised: 25 Sep 2011 \\
Accepted: 05 Oct 2011 \\
\hline
\end{tabular}

Keywords:

Drug Users

Food Intake Regulation

Nutritional Status

\begin{abstract}
A B S T R A C T
Background: Drug addiction is a lifestyle disease. An assessment of the nutritional state of addicts is often done in parallel to their medical treatment.

objectives: The aim of the present study was to investigate the nutritional status of drug addicts.

Patients and Methods: This study was conducted among 54 drug addicts ( 47 men and 7 women) who sought detoxification treatment at the Central Drug Addiction Treatment Hospital in center of drug dependency treatment (Baharan Hospital) in Zahedan, Iran. Age, body weight, and height were measured. Body mass index (BMI) was calculated by dividing body weight $(\mathrm{kg})$ by the square of the height $\left(\mathrm{m}^{2}\right)$. The percentile of the BMI indicator dictated the nutritional status in the subjects. The amount of food consumed was determined according to the number of servings consumed in the different food groups and was compared to the recommended allowances given by the Food Guide Pyramid.

Results: The mean age, body weight, height, and BMI were $34.4 \pm 9.7$ years, $63.1 \pm 10.1 \mathrm{~kg}$, $171.1 \pm 11.6 \mathrm{~cm}$, and $21.8 \pm 4.4 \mathrm{~kg} / \mathrm{m}^{2}$, respectively. According to the percentile status of the BMIs, the results showed that $35.2 \%, 20.4 \%, 37 \%$, and $7.4 \%$ of subjects were wasting, at risk of wasting, normal, or overweight, respectively. When their intake was compared to the Food Guide Pyramid, $72.2 \%$ of the subjects showed a deficiency in the bread and cereal group, $67.2 \%$ in vegetables, $57.4 \%$ in fruits, $40.7 \%$ in milk and dairy products, and $24.1 \%$ in the meat group.

Conclusions: The present study revealed different degrees of malnutrition among drug
\end{abstract} addicts with multiple deficiencies in both macro- and micronutrients.

Copyright $\odot 2012$ Kowsar Corp. All rights reserved.

-Implication for health policy/practice/research/medical education:

Since there was not any information about nutritional status in the drug addicts in this area; The aim of this study was to investigate the nutritional status in them. It seems the results of this study can help in treatment and health promotion of this affected group

Please cite this paper as:

Karajibani M, Montazerifar F, Shakiba M. Evaluation of Nutritional Status in Drug Addicts Referred to the Center of Drug Dependency Treatment in Zahedan. Int J High Risk Behav Addict. 2012; 1(1):xxxxx. DOI: 10.5812/ijhrba.4176

\section{Background}

Drug addiction is a lifestyle disease that can lead to social and public health problems (1). Many studies on addicts have demonstrated nutritional deficiencies, in-

\footnotetext{
* Corresponding author: Mansour Karajibani, Department of Nutrition, Zahedan University of Medical Sciences, Zahedan, IRIran. Tel:+ 98-54134145527, Fax:+98 -5413414552, E-mail: mkarajibani@gmail.com

DOI:10.5812/ijhrba.4176

Copyright $\odot 2012$ Kowsar Corp. All rights reserved.
}

cluding weight loss and changes in dietary patterns (2). Apparently, drugs do not affect energy intake directly, but probably affect the nutritional quality of the meals an addict chooses (3). The protein calorie malnutrition of many drug addicts is linked to factors such as female gender, intensity of the addiction, anorexia, poor diet, and an alteration of the addict's social and familial links (3). Nutritional deficiencies can severely and permanently affect different organ functions; in particular, energy, 
protein, vitamin, and mineral deficiencies can cause several nutritional disorders. Many drug addicts suffer from calorie and protein malnutrition $(3,4)$. The prevalence of malnutrition in drug addicts and the influence of their drug habit and lifestyle on their nutritional indices have been investigated (5).

Many studies have shown a relationship between drug addiction and education, income, and body mass index (BMI) (2). Most addicts suffer from nutritional and metabolic disorders. It is necessary to consider a proper diet based on individual characteristics that lead to different physiological changes. Addicts need good health, inspiration, support, and proper nourishment. The aim of the present study was to investigate the nutritional status in drug addicts referred to a center for the treatment of drug dependence.

\section{Objectives}

The aim of the present study was to investigate the nutritional status in drug addicts.

\section{Patients and Methods}

\subsection{Subjects}

In this descriptive, cross-sectional study, 54 drug addicts (47 men and 7 women) were enrolled during the period of January to April 2007. All persons referred to the Center of Drug Dependency Treatment of Zahedan were informed of the study and asked for their consent to participate. They were multi-drug users of substances such as heroin, opiates, crack, and morphine, and they sought detoxification in the Central Drug Addiction Treatment Hospital (C.D.A.T) of Baharan, Zahedan, Iran. All were seen by a specialist, who described the study they would enter. The hospital specializes in detoxification therapy and provides facilities for drug addicts. Age, body weight, and barefoot height were measured using digital scales (Seca, Germany) and a non-stretch tape fixed to a flat vertical wall. BMI was calculated by dividing body weight $(\mathrm{kg})$ by the square of the height $\left(\mathrm{m}^{2}\right)$, and its percentile position in the BMI indicator was determined.

\subsection{Nutritional Assessment}

The cutoff points used to determine nutritional status in the subjects were the following: BMI $\leq 5^{\text {th }}$ percentile, wasting; $5^{\text {th }}$ to $<15^{\text {th }}$, risk of wasting; $15^{\text {th }}$ to $<85^{\text {th }}$, normal weight; $>85^{\text {th }}$ to $\leq 95^{\text {th }}$, overweight; and $>95^{\text {th }}$, obese $(6$, $7)$. The subjects responded to the nutritional questionnaire based on the Pyramid Food Guidance System. They recalled the different food groups from which they consumed at 2 different time points. During the course of the study, a nutritionist and educated expert regularly advised the subjects. The food questionnaire, which provided information about food consumption, was administered by a trained nutritionist.

Before putting the data into a computer, standard reference tables were used to convert household portions to grams of consumed food. The Food Guide Pyramid offers a method for determining appropriate patterns for daily food choices based on the 5 major food groups from which recommended consumptions are selected: bread and cereals, 6-11 exchanges/day; fruits, 2-4 exchanges/ day; vegetables, 3-5 exchanges/day; milk and dairy products, 2-3 exchanges/day; meat, egg, dried beans, nuts, and substitutes, 2-3 exchanges/day; and small amounts of fats, oils, and sweets (8).

For each case, the food intake was determined according to the number of servings reported in each food group. These amounts were then compared to the recommended allowances from the Food Guide Pyramid.

\subsection{Statistical Analysis}

Results are expressed as Mean \pm SD. The statistical analysis was performed using SPSS 11.5 software, with ethical points for the subjects duly observed.

\section{Results}

Of the 54 drug addicts, $87 \%$ were men and $13 \%$ women, with ages ranging from 19 to 67 years. Mean age, body weight, height, and BMI were $34.4 \pm 9.7$ years, $63.1 \pm 10.1 \mathrm{~kg}$, $171.1 \pm 11.6 \mathrm{~cm}$, and $21.8 \pm 4.4 \mathrm{~kg} / \mathrm{m}^{2}$, respectively (Table 1 ).

\begin{tabular}{lll}
\hline \multicolumn{2}{l}{ Table 1. Characteristics of the Drug Addicts } \\
\hline & Mean \pm SD & Min-Max \\
\hline Age, y & $34.4 \pm 9.7$ & $19-67$ \\
Body weight, kg & $63.1 \pm 10.1$ & $46-58$ \\
Height, cm & $171.1 \pm 11.6$ & $139-189$ \\
BMI $^{\mathrm{a}}, \mathrm{kg} / \mathrm{m}^{2}$ & $21.8 \pm 4.4$ & $16.2-26.1$ \\
\hline
\end{tabular}

a Abbreviation: BMI, Body mass indext

Table 2. Nutritional Status of Drug Addicts Based on Percentile of Body Mass Index

\begin{tabular}{ll}
\hline & No. $(\%)$ \\
\hline Wasting & \\
Men & $19(40.4)$ \\
Women, & $0(0)$ \\
Total & $19(35.2)$ \\
Risk of wasting & \\
Men & $10(21.3)$ \\
Women & $1(14.3)$ \\
Total & $11(20.4)$ \\
Normal & \\
Men & $16(34.1)$ \\
Women & $4(57.1)$ \\
Total & $20(37)$ \\
Overweight & \\
Men & $2(4.2)$ \\
Women & $2(28.6)$ \\
Total & $4(7.4)$ \\
Total & \\
Men & $47(87 \%)$ \\
Women & $7(13 \%)$ \\
Total & $54(100)$ \\
\hline
\end{tabular}




\begin{tabular}{|c|c|c|c|}
\hline & Serving & No. $(\%)$ & Recommended Allowance \\
\hline \multirow[t]{3}{*}{ Bread and cereals } & & & 6-11 exchange \\
\hline & $<6$ exchange & $39(72.2)$ & \\
\hline & $>6$ exchange & $15(27.8)$ & \\
\hline \multirow[t]{3}{*}{ Vegetables } & & & 3-5 exchange \\
\hline & $<3$ exchange & $44(67.2)$ & \\
\hline & $>3$ exchange & $31(32.8)$ & \\
\hline \multicolumn{4}{|l|}{ Fruits } \\
\hline & $<2$ exchange & $31(57.4)$ & \\
\hline & $>2$ exchange & $33(42.6)$ & \\
\hline \multirow[t]{3}{*}{ Milk and dairy products } & & & 2-3 exchange \\
\hline & $<2$ exchange & $22(40.7)$ & \\
\hline & $>2$ exchange & $32(59.3)$ & \\
\hline \multirow[t]{3}{*}{ Meat, egg, and substitutes } & & & 2-3 exchange \\
\hline & $<2$ exchange & $13(24.1)$ & \\
\hline & $>2$ exchange & $41(75.9)$ & \\
\hline
\end{tabular}

The BMI results showed that $40.4 \%$ men and $0 \%$ women were wasting; $21.3 \%$ men and $14.3 \%$ women were at risk of wasting; $34.1 \%$ men and $57.1 \%$ women were of normal weight; and $4.2 \%$ men and $28.6 \%$ women were overweight (Table 2).

The results also revealed the following mean consumptions in the different food groups: bread, rice, and cereals, 4.8 exchanges/day; vegetables, 0.8 exchanges/day; fruits, 1.3 exchanges/day; milk and dairy products, 1.9 exchanges/day; meat, eggs, dried beans, nuts, and substitutes, 1.9 exchanges/day. According to the standard Food Guide Pyramid, $72.2 \%$ of the subjects were deficient in the bread and cereal group; $67.2 \%$, in vegetables; $57.4 \%$, in fruits; $40.7 \%$, in milk and dairy products; and $24.1 \%$, in meat (Table 3).

\section{Discussion}

The results of this study demonstrated malnutrition of different degrees: mild, moderate, and severe. As indicated by the BMIs, $65 \%$ of the subjects were wasting. Nazrul Islam et al. have reported that $60-74 \%$ of drug addicts had below normal BMI and showed clinical signs of nutritional deficiency (1). Many addicts have caloric and protein malnutrition related to their poor intake of food and liquids $(1,3)$. Data from the Third National Health and Nutrition Examination Survey (NHANES III), 1988-1994, showed marijuana users to have BMIs slightly lower, and they also consumed less fruit and cheese (9).

The comparison of food intake with the Food Guide Pyramid demonstrated both macro- and micronutrient deficiencies. Alves et al. have suggested a relationship between nutritional status and food consumption of addicts in methadone maintenance treatment (2). Those findings agree with the study by Smith et al. that noted low intakes of fruits and vegetables in drug users (10). The failure to meet healthy daily minimum intake levels of grains, fruits, and vegetables may be due to the fact that drug addicts focus only on satiety when they have feelings of scorn about their next meal (2). The results are supported by another study which showed low intakes of fruits and vegetables in drug users (11). Because the patients in this study are undergoing treatment and take drugs regularly, they need to take vitamins and minerals to improve their health. Some of the opiate drugs reduce the absorption of such vitamins as A, C, and E. Deficiencies in antioxidant vitamins in drug addicts have previously been reported (11). A number of following components in foods have been found to have antioxidant properties; they have specific activities and usually work synergistically to improve the antioxidant ability of the body (12). The findings here showed the ratio of intake of cereals and rice to be too low for producing energy. Although, the calorie intake was not determined in this study, lack of energy intake can cause deficiency in such macro- and micronutrients such as proteins, essential fatty acids, vitamins, and minerals. Santolaria-Feranoez et al. found the mean caloric intake to be $978 \pm 89 \mathrm{kcal} /$ day in females and $1256 \pm 64 \mathrm{kcal} /$ day in males. Acute organic pathology aggravates the poor nutritional status of drug addicts (3). In tandem with the deficient intake from the cereal group, a deficient consumption of food from the milk and dairy group and the meat groups was observed. These findings demonstrate the poor pattern of food consumption in these patients. In drug addicts, who often have amino acid deficiency, the conversion process from protein to amino acids can slow or stop. Therefore, a deficiency of protein sources, especially animal protein can lead to malnutrition. Balanced meals high in complex carbohydrate, protein, and fiber and low in fat, with adequate calories for a healthy body weight, are recommended (8). An assessment of nutritional status includes any combination of biochemical and body composition measurements, dietary intake assessment, and metabol- 
ic studies (13). In conclusion, the present study revealed that drug addicts had different degrees of malnutrition and multiple nutrient deficiencies. Therefore, in parallel to clinical management, programs to promote an adequate nutritional status and to modify lifestyles, with supporting nutritional and educational programs, are recommended.

\section{Acknowledgments}

The authors would like to thank the experts and emergency section staff at the Central Drug Addiction Treatment Hospital (C.D.A.T) of Baharan Zahedan, Iran for their kind cooperation, as well as the patients and healthy subjects who willingly participated in the study.

\section{Financial Disclosure}

The authors have no financial conflicts of interest.

\section{Funding/Support}

The authors have not received any support.

\section{References}

1. Nazrul Islam SK, Jahangir Hossain K, Ahmed A, Ahsan M. Nutritional status of drug addicts undergoing detoxification: prevalence of malnutrition and influence of illicit drugs and lifestyle. Brit J Nutr. 2002;88(5):507-13.

2. Alves D, Costa AF, Custódio D, Natário L, Ferro-Lebres V, Andrade F. Housing and employment situation, body mass index and di- etary habits of heroin addicts in methadone maintenance treatment. Association for the Application of Neuroscientific Knowledge to Social Aims, AU-CNS. 2011;13(1):1592-638.

3. Santolaria-Fernandez FJ, Gomez-Sirvent JL, Gonzalez-Reimers CE, Batista-Lopez JN, Jorge-Hernandez JA, Rodriguez-Moreno F, et al. Nutritional assessment of drug addicts. Drug Dep.1995;38(1):11-8.

4. Morabia A, Fabre J, Chee E, Zeger S, Orsat E, Robert A. Diet and opiate addiction: a quantitative assessment of the diet of noninstitutionalized opiate addicts. Brit J Addic. 1989;84(2):173-80.

5. Varela P, Marcos A, Ripoll S, Santacruz I, Requejo AM. Effects of human immunodeficiency virus infection and detoxification time on anthropometric measurements and dietary intake of male drug addicts. Am J Clinic Nutr. 1997;66(2):509S-14S.

6. Swallen KC, Reither EN, Haas SA, Meier AM. Overweight, obesity, and health-related quality of life among adolescents: the National Longitudinal Study of Adolescent Health. Pediatrics. 2005;115(2):340-7.

7. Switzerland G. Obesity: preventing and managing the global epidemic. Report of a WHO consultation. World Health Organization technical report series. 2000;894:i-xii, 1-253.

8. Mahan LK E-sS. Krause's food, nutrition, and diet therapy. 12 ed. the University of Michigan: Elsevier, Sounders; 2004.

9. Smit E, Crespo CJ. Dietary intake and nutritional status of US adult marijuana users: results from the Third National Health and Nutrition Examination Survey. Pub Health Nutr. 2001;4(3):781-6.

10. Smit E, Graham NM, Tang A, Flynn C, Solomon L, Vlahov D. Dietary intake of community-based HIV-1 seropositive and seronegative injecting drug users. J Nutrition. 1996;12(7-8):496-501.

11. Nazrul Islam SK, Jahangir Hossain K, Ahsan M. Serum vitamin E, $C$ and $A$ status of the drug addicts undergoing detoxification: influence of drug habit, sexual practice and lifestyle factors. Euro J Clinic Nutr. 2001 Nov;55(11):1022-7.

12. Bagchi K, Puri S. Free radicals and antioxidants in health and disease. East Mediterr Health J.1998;4(350):60.

13. Smit E, Tang A. Nutritional assessment in intravenous drug users with HIV|AIDS. J Acquir Immune Defic Syndr;25 (Suppl 1):S62-9. 